\title{
Personality organization and sense of identity across clinical and non-clinical populations
}

\author{
Aleksandra Pilarska ${ }^{A, C, D, E, F}$, Anna Suchańska $a^{A, B, D, E, F}$ \\ Institute of Psychology, Adam Mickiewicz University in Poznań, Poznan, Poland
}

\section{BACKGROUND}

The aim of the study was to evaluate the usefulness of the core dimensions of personality organization introduced by Kernberg and the basic aspects of the sense of personal identity as criteria of mental health, and to verify those theses of Kernberg's theory that link the maturity of one's sense of identity with one's development in the domains of functioning considered the core dimensions of personality. The main predictions were that (a) the core dimensions of personality organization and the basic aspects of the sense of identity would discriminate between patients diagnosed with mental disorders and individuals drawn from the general population, and (b) lower levels of personality functioning would be related to weakening and disorganization of the sense of identity.

\section{PARTICIPANTS AND PROCEDURE}

The sample consisted of 94 persons from the general population and 49 psychiatric patients diagnosed with neurotic disorders, affective disorders, personality disorders, and psychotic disorders. Two research tools were used to collect data: the Inventory of Personality Organization (IPO) and the Multidimensional Questionnaire of Identity (MQI).

\section{RESULTS}

Statistical analysis revealed significant differences in the levels of personality dimensions and the sense of personal identity between participants from the general population and psychiatric patients. Moreover, the results confirmed the role of the level of personality organization as a factor responsible for the differences in the strength of the sense of identity.

\section{CONCLUSIONS}

The obtained results support the assumptions of Kernberg's personality organization model and indicate the usefulness of the central personality dimensions outlined in Kernberg's model for the diagnosis of personality pathology.

\section{KEY WORDS}

psychopathology; level of personality organization; sense of identity

Corresponding Author - Aleksandra Pilarska, Ph.D., Institute of Psychology, Adam Mickiewicz University in Poznań, 89 Szamarzewskiego Str., 60-568 Poznan, Poland, e-mail: alpila@amu.edu.pl

AUthors' CONTRIBUtion - A: Study design - B: Data collection - C: Statistical analysis - D: Data interpretation .

E: Manuscript preparation · F: Literature search · G: Funds collection

to Cite this ARTicle - Pilarska, A., \& Suchańska, A. (2016). Personality organization and sense of identity across clinical

and non-clinical populations. Current Issues in Personality Psychology, 4(1), 31-40.

RECEIVED 25.11.2015 - REVIEWED 28.12.2015 - ACCEPTED 04.01.2016 · PUBLISHED 04.02.2016 


\section{BACKGROUND}

A psychiatric diagnosis of mental disorder is established on the basis of descriptive parameters, which relate to specific signs and symptoms of disorders, and translate into the diagnostic criteria of the ICD (International Statistical Classification of Diseases and Related Health Problems) and DSM (Diagnostic and Statistical Manual of Mental Disorders) classification systems. However, more and more emphasis has been placed on the clinical utility of structural diagnosis, which goes beyond the mere description of symptoms (Morey et al., 2011a, 2011b). Perhaps the most obvious evidence of this is the inclusion in the personality disorder section of the DSM- 5 of the level of personality functioning (i.e., the severity of disturbances in self and interpersonal functioning) as the basic criterion which determines whether a diagnosis of a personality disorder is merited (Grabski \& Gierowski, 2012; Morey et al., 2011a, 2011b).

The theoretical proposition that provides in-depth understanding of the organization and dynamics of mental processes is the psychodynamic model of personality functioning developed by Kernberg (1975, 1984, 1996). Kernberg specified the following dimensions as defining and differentiating the personality organization levels: identity integration-diffusion, defense mechanisms, reality testing, moral functioning, and object relationship patterns. The present investigation is an attempt at verifying those theses of Kernberg's theory that link levels of personality organization with specific ways of experiencing one's own identity.

\section{PERSONALITY DEVELOPMENT AND THE SENSE OF IDENTITY - THE NORM AND PATHOLOGY}

According to Kernberg, personality develops in the course of dynamic interaction between temperamental and characterological factors. "From the psychoanalytic perspective [...] character refers to the behavioral manifestations of ego identity, whereas the subjective aspects of ego identity, that is, the integration of the self concept and of the concept of significant others, are the intrapsychic structures that determine the dynamics. Organization of character also includes all the behavioral aspects of [...] ego functions and ego structures" (Kernberg, 1996, p. 110). Apart from character and temperament, the structure of personality is determined by the consolidation of various levels of the superego as well as by the motivational forces of the id, powerful and having a potential for conflict. Personality is therefore understood as dynamic integration of temperamentally and characterologically determined behavioral dispositions and an internalized system of values. The degree to which the ego and the superego are capable of integrating the id's impulses through sublimation determines the adaptive potential of personality as well as the level of its organization and health.

The integration takes place in several stages, in the course of the processes of internalization of selfobject-affect units: starting with the introjection of primitive, isolated traces of selfobject experiences, through a more mature mechanism of identification, which requires the capacity to differentiate self from nonself and to recognize the role aspect of social relationships, to ego identity. The most mature form of internalization, operating within the ego, comprises its consolidated structures, bound by a sense of self-continuity and a coherent overall sense of self and others. In the case of identity diffusion, the relations with internal objects, which together constitute the sense of self, are black-and-white, with extreme valuations of entirely good or entirely bad attributed to them. The absence of a central and consistent sense of self makes the experience of oneself (and others) superficial, fragmentary, and changeable.

Thus, the first criterion of a healthy personality is the achievement of a sense of self that is continuous in space and time. The second one is the growing ego strength, which enables the control and sublimation of impulses and affects, thereby allowing greater autonomy. The third one is an integrated and mature superego, ensuring a stable value system and a sense of responsibility. The fourth one is adequate regulation of libidinal and aggressive impulses, which consists in the full expression of sensual and sexual needs combined with tenderness for and emotional commitment to the loved one. The now sublimated aggressive impulses can be expressed in the form of assertiveness.

The adequate development of these capacities ensures the mature (normal) organization of personality. Failures in the successive stages of this process lead to personality disorders involving the inhibition of the development of functions specific to a particular phase of the life cycle: from serious deficits in reality testing, the persistence of primitive forms of affect and defense, as well as the lack of self-object differentiation and the lack of integration of self- and object-representations, to a dysfunctional, strict superego, which induces intense feelings of anxiety, guilt, and rage. The type and severity of these disturbances became the basis for distinguishing three main levels of personality organization: psychotic, borderline, and neurotic (Kernberg, 1996). The lowest, psychotic level of personality organization is characterized by a lack of integration of the representations of self and others (i.e., identity diffusion), by the loss of reality testing (which includes recognition of the boundary between self and other, internal and external), by the dominance of primitive defense mechanisms centering around splitting, and by a lack 
of impulse control. The intermediate level, borderline personality organization, also involves identity diffusion and primitive defenses. It differs, however, from the psychotic level in having essentially intact reality testing. Numerous patients also exhibit deficits in superego functioning, which, combined with identity disorders, considerably disorganize their social relations. Ego immaturity manifests itself in this case also in weak tolerance of anxiety and weak impulse control. At the most healthy pole of Kernberg's continuum are individuals with normal identity integration, exhibiting a predominance of mature defenses (based on repression) and stable reality testing.

Summing up, according to Kernberg's theory, what is essential to the formation of a sense of identity is the replacement of splitting by repression and the achievement of the integration of self- and object-representations. This also serves as a sign of higher-level personality organization, at least the neurotic one. The developed sense of identity is then accompanied by the capacity for deeper relationships with people, and a sufficiently strong ego enables anxiety tolerance and impulse control, with possible episodes of guilt over sexual intimacy. Disturbances in the sense of identity, according to Kernberg, are related to the psychotic and borderline levels. They may be experienced as a sense of depersonalization, inner void, a loss of boundaries or continuity over time, or fragile self-worth (Kernberg, 1975, 1984, 1996; Millon \& Davis, 2005).

\section{RESEARCH QUESTIONS AND HYPOTHESES}

The present study concerned the personality and identity characteristics of individuals from the general (non-clinical) and clinical populations. It was aimed at verifying those theses of Kernberg's theory that link the maturity of one's sense of identity with one's development in the domains of functioning considered the "core" of Kernberg's theory of personality organization. Therefore, the main questions of this study were whether levels of personality organization differ in terms of subjective experience of identity, as Kernberg's model postulates, and what relationships exist between particular dimensions of personality (reality testing capacity, maturity of defense mechanisms, intensity of aggression, and integration of moral values) and particular identity-related senses (senses of having inner contents, uniqueness, one's own boundaries, coherence, continuity over time, and self-worth).

Given the importance of the dynamics of personality and identity in psychiatric diagnosis, the objective of the study was also to examine whether the structure of personality and the way of experiencing one's own identity differ between individuals diag- nosed with mental disorders and individuals drawn from the general population.

On the basis of theoretical considerations, it was expected that lower levels of personality organization - marked by the use of primitive defense mechanisms, a lack of a sense of reality, disintegration of self-representations, and aggressiveness - would be accompanied by a weaker sense of personal identity. Furthermore, it was predicted that lower levels of personality organization and a weakening of the sense of personal identity would occur more frequently among patients diagnosed with mental disorders.

\section{PARTICIPANTS AND PROCEDURE}

\section{PARTICIPANTS}

A total of 143 people participated in this study $(63.60 \%$ females). Their ages ranged from 19 to $73(M=35.37$ years, $S D=12.02$ years $)^{1}$.

The non-clinical group included 94 participants between the ages of 21 and $73(M=32.02$ years, $S D=10.96$ years). Of this sample, $59.60 \%$ were female. The criterion for inclusion in the group was the attainment of the age of majority. Most of the participants reported that they had higher education levels (71.30\%). Given the epidemiological data on the prevalence of mental disorders in Poland (Moskalewicz, Kiejna, \& Wojtyniak, 2012), it can be assumed that this group was dominated by individuals without mental disorders.

The clinical group consisted of 49 participants whose ages ranged from 19 to $66(M=41.65$ years, $S D=11.49$ years); $71.40 \%$ were female. These were currently hospitalized patients from three different centers for psychiatric medicine located in the Greater Poland region. The criterion for inclusion in the group was a clinical diagnosis of at least one mental disorder according ICD-10. It included neurotic disorders (7 patients were diagnosed with mixed depressive-anxiety disorder, 3 patients were diagnosed with generalized anxiety disorder, 2 patients were diagnosed with phobic anxiety disorder, 2 patients were diagnosed with anxiety disorder without further specification, 1 patient was diagnosed with somatoform disorder, and 1 patient was diagnosed with dissociative disorder), affective disorders (4 patients were diagnosed with major depressive disorder, 3 patients were diagnosed with bipolar disorder, 2 patients were diagnosed with recurrent depressive disorder, and 1 patient was diagnosed with organic mood disorder), personality disorders (7 patients were diagnosed with borderline personality disorder, 1 patient was diagnosed with antisocial personality disorder, and 3 patients were diagnosed with a general personality disorder without further specification), and psychotic disorders (9 patients were diagnosed 
with schizophrenia, 2 patients were diagnosed with delusional disorder, and 1 patient was diagnosed with schizoaffective disorder $)^{2}$. No patients had acute psychotic symptoms, and all were judged fit to participate in the study by the treating clinician.

Study participation was voluntary and anonymous.

\section{MEASURES}

The following measures were used in the study.

The Sense of Identity. Sense of identity, defined as a comprehensive, intuitive-reflective stance toward oneself that represents a cumulative effect of recurring ways of experiencing and understanding oneself, was measured using the Multidimensional Questionnaire of Identity (MQI; Pilarska, 2012; Pilarska $\&$ Suchańska, 2013). The questionnaire comprises a total of 38 items, rated on a 4-point scale and related to six basic categories of the sense of identity: sense of having inner contents, associated with a sense of ownership and access to one's own thoughts, feelings, motives, attitudes, etc. (accessibility subscale); sense of uniqueness, associated with a sense of one's own specificity and distinctness (specificity subscale); sense of one's own boundaries, associated with the capacity to differentiate self from nonself (separateness subscale); sense of coherence, associated with a sense of congruity within one's significant inner content (coherence subscale); sense of continuity over time, associated with a sense of constancy of the self and being the same person, despite the passage of time and changes going on within the person (stability subscale); and sense of self-worth, associated with a sense of self-satisfaction and a belief in the possibility of achieving one's personal goals (valuation subscale). Each subscale is scored by averaging items within the subscale. The minimum and maximum scores possible on each subscale range from 0 to 3, with higher scores representing a higher sense of identity in each specified area. Cronbach's $\alpha$ coefficients for the subscales range from .62 to .86 (average: .74; Pilarska, 2012).

Personality Organization. The functions determining the level of personality organization were assessed via an adapted version of the Inventory of Personality Organization (IPO; Clarkin, Foelsch, \& Kernberg, 2001; Izdebska \& Pastwa-Wojciechowska, 2013). The inventory consists of 83 items rated on a 5-point scale ranging from never true to always true and referring to: (1) the maturity of the dominant defense mechanisms (primitive defenses subscale), (2) an individual's ability to develop a stable and complex concept of self and others (identity diffusion subscale), (3) an individual's capacity to distinguish self from nonself, intrapsychic from external stimuli, and to maintain empathy with ordinary social criteria of reality (reality testing subscale), (4) aggressive attitudes and behaviors, and aggres- sion against oneself (aggression subscale), and (5) hostile and antisocial attitudes (i.e., superego pathology; moral values subscale). Scores are calculated by summing up the ratings for each subscale. The minimum and maximum scores range from 16 to 80 for the primitive defenses subscale, from 21 to 105 for the identity diffusion subscale, from 20 to 100 for the reality testing subscale, from 18 to 90 for the aggression subscale, and from 11 to 55 for the moral values subscale. Higher scores indicate greater personality pathology. The five subscales of the Polish version of the IPO demonstrated reasonable internal consistency, with a Cronbach's $\alpha$ varying from .78 to .91 (average: .85; Izdebska \& Pastwa-Wojciechowska, 2013).

\section{RESULTS}

Statistical analysis was based on correlations, $\chi^{2}$ tests of independence, and parametric (where the normality assumption was justified) or nonparametric tests of the difference between means.

\section{PRESENCE OF MENTAL DISORDERS \\ IN RELATION TO PERSONALITY ORGANIZATION AND SENSE OF IDENTITY}

Table 1 presents the means and standard deviations of all variables for the total sample and for non-clinical and clinical groups separately. Results of between-group comparisons showed that the clinical group scored significantly higher on all dimensions of personality, which suggests a higher degree of personality pathology: $t(78)=-4.65, p<.001$ for primitive psychological defenses; $t(141)=3.78, p<.001$ for identity diffusion; $U=1166.00, p<.001$ for reality testing; $U=1459.50, p<.001$ for aggression; and $t(141)=-2.85, p=.005$ for moral values. As regards the analyzed identity-related senses, the clinical group scored significantly lower - as compared to the non-clinical group - on sense of continuity over time, $U=1518.00, p<.001$, but significantly higher on sense of inner contents, $U=1770.50, p=.020$. Measures of effect size suggest particularly strong impacts of the presence of mental disorders on maturity of defense mechanisms and reality testing skills.

An analysis of gender differences by means of the Mann-Whitney $U$-test revealed no significant gender differences in any of the variables considered $(p>.070)$. Differences between young (i.e., younger than 35 years), middle (i.e., ages 36-55 years), and older adults (i.e., ages 56 and older) approached significance only for the sense of inner contents, $\chi^{2}(2)=11.12, p=.004$. Young adults scored lower than middle-aged adults, $U=1245.50, p<.001$; older adults did not differ significantly from either of the other age groups $(p>.157)$. 
Table 1

Descriptive statistics of study variables and comparison of non-clinical and clinical samples

\begin{tabular}{|c|c|c|c|c|c|c|}
\hline \multirow[t]{2}{*}{ Variable } & $\begin{array}{l}\text { Overall } \\
(n=143)\end{array}$ & $\begin{array}{l}\text { Non-clinical } \\
\quad(n=94)\end{array}$ & $\begin{array}{l}\text { Clinical } \\
(n=49)\end{array}$ & \multirow[t]{2}{*}{$t$} & \multirow[t]{2}{*}{$U$} & \multirow[t]{2}{*}{$d$} \\
\hline & $M(S D)$ & $M(S D)$ & $M(S D)$ & & & \\
\hline PD & $40.06(8.39)$ & $37.70(6.96)$ & 44.59 (9.09) & $-4.65^{* * *}$ & & 0.83 \\
\hline ID & $53.82(12.23)$ & $51.15(11.03)$ & $58.94(12.89)$ & $-3.78^{* * *}$ & & 0.67 \\
\hline RT & $39.63(10.94)$ & $36.48(9.02)$ & $45.69(11.80)$ & & $1166.00^{* * *}$ & 0.88 \\
\hline AG & $29.04(6.80)$ & $27.27(4.91)$ & $32.45(8.48)$ & & $1459.50^{* * *}$ & 0.63 \\
\hline MV & $25.54(5.43)$ & $24.63(5.19)$ & $27.29(5.50)$ & $-2.85^{* *}$ & & 0.51 \\
\hline SIC & $1.82(0.37)$ & $1.75(0.20)$ & $1.94(0.56)$ & & $1770.50^{*}$ & 0.40 \\
\hline SU & $1.48(0.36)$ & $1.50(0.25)$ & $1.46(0.51)$ & & 2124.50 & 0.13 \\
\hline SOB & $1.46(0.37)$ & $1.49(0.26)$ & $1.40(0.52)$ & & 2142.50 & 0.12 \\
\hline $\mathrm{SC}$ & $1.55(0.33)$ & $1.51(0.22)$ & $1.64(0.47)$ & & 1916.00 & 0.28 \\
\hline SCT & $1.68(0.64)$ & $1.80(0.62)$ & $1.44(0.61)$ & & $1518.00^{* * *}$ & 0.59 \\
\hline SSW & $1.58(0.44)$ & $1.60(0.23)$ & $1.53(0.68)$ & & 2218.50 & 0.06 \\
\hline
\end{tabular}

In order to identify subgroups of participants with distinctive personality organizations and configurations of identity-related senses, two-stage cluster analysis was carried out.

Three groups were identified with statistically significant differences in all the functions that determine the type of personality organization $(p<.001)$. Cluster 2 corresponds to the lowest - within the study sample - level of personality organization (i.e., the least mature). It is marked by the dominance of primitive defense mechanisms, high identity diffusion, severe deficits in reality testing and superego functioning, and a high level of aggression. Cluster 3 represents the highest level of personality organization in the study group (i.e., the most mature). A less frequent use of primitive defenses, relatively integrat- ed identity, retained reality testing, and a low level of aggression or hostile and antisocial attitudes are observed in this case. Cluster 1 (i.e., the medium one) is characterized by scores that are close to the total mean in all personality dimensions (see Table 2).

To examine the relationship between the type of personality organization and the presence of mental disorders (i.e., belongingness to either the non-clinical or clinical group), a $\chi^{2}$ test was performed. The data presented in Table 3 show that this relationship was significant, $\chi^{2}(2)=17.55, p<.001$. The most mature personality cluster (cluster 3 ) is composed, in the vast majority $(82.20 \%)$, of individuals from the non-clinical group, whereas the least mature personality cluster (cluster 2 ) is dominated by individuals from the clinical group (60.50\%). A similar percent-

Table 2

Comparison of clusters with different profiles of personality dimensions

\begin{tabular}{|c|c|c|c|c|c|c|c|}
\hline Variable & $\begin{array}{c}\text { Personality } \\
\text { Cluster } 1 \\
\quad(n=60)\end{array}$ & $\begin{array}{c}\text { Personality } \\
\text { Cluster } 2 \\
(n=38)\end{array}$ & $\begin{array}{c}\text { Personality } \\
\text { Cluster } 3 \\
\quad(n=45)\end{array}$ & $F$ & $H$ & Post-hoc & $\eta^{2}$ \\
\hline & $M(S D)$ & $M(S D)$ & $M(S D)$ & & & & \\
\hline PD & 39.38 (5.65) & $48.53(7.15)$ & $33.80(6.22)$ & $57.72^{* * *}$ & & $3<1<2$ & .45 \\
\hline ID & $53.72(5.95)$ & $67.74(9.70)$ & $42.19(7.10)$ & $120.87^{* * *}$ & & $3<1<2$ & .63 \\
\hline RT & 38.03 (7.13) & $52.66(9.06)$ & $30.77(4.32)$ & & $89.22^{* * *}$ & $3<1<2$ & .63 \\
\hline AG & $29.11(4.72)$ & $36.05(6.31)$ & $23.04(2.54)$ & & $73.14^{* * *}$ & $3<1<2$ & .52 \\
\hline MV & $25.25(4.25)$ & $31.24(3.87)$ & $21.10(3.14)$ & $72.57^{* * *}$ & & $3<1<2$ & .51 \\
\hline
\end{tabular}

Note. PD - primitive defenses, ID - identity diffusion, RT - reality testing, AG - aggression, MV - moral values, ${ }^{* * *} p<.001$ 
age of individuals belonging to the non-clinical and clinical groups fell in the medium personality cluster (cluster 1).

Analogous analyses were performed for the sense of identity. The classification analysis distinguished three clusters that differed significantly in the intensity of all identity-related senses $(p<.001)$. The largest cluster - cluster 1 - comprises participants with harmonized structure, who scored close to the overall mean on all identity-related senses. Participants in cluster 2 have disharmonized structure with evidence of some rigidity - they are marked by strong senses of having inner contents, coherence, and selfworth, with relatively weaker senses of continuity over time, uniqueness, and one's own boundaries. Those in cluster 3 are characterized by strong disorganization of the sense of identity and clear deficits in most identity-related senses (see Table 4).
To examine the relationship between the type of configuration of identity-related senses and the presence of mental disorders, a chi-square test was used. The test results presented in Table 5 indicate that this relationship was significant, $\chi^{2}(2)=87.45, p<.001$. Participants from the non-clinical group dominate $(88.50 \%)$ in the cluster characterized by mean scores on all identity-related senses (cluster 1), whereas the remaining two clusters (clusters 2 and 3) contain almost exclusively individuals from the clinical group (95.20\% and $94.40 \%$, respectively).

\section{LEVEL OF PERSONALITY ORGANIZATION AND SENSE OF IDENTITY}

To investigate the relations between dimensions of personality and identity-related senses, first, correla-

Table 3

Analysis of association between personality clusters and sample membership

\begin{tabular}{|c|c|c|c|c|c|}
\hline & & $\begin{array}{c}\text { Personality } \\
\text { Cluster } 1\end{array}$ & $\begin{array}{c}\text { Personality } \\
\text { Cluster } 2\end{array}$ & $\begin{array}{c}\text { Personality } \\
\text { Cluster } 3\end{array}$ & Overall \\
\hline \multirow{3}{*}{$\begin{array}{l}\text { Non-clinical } \\
\text { sample }\end{array}$} & $n$ & 42 & 15 & 37 & 94 \\
\hline & $\%$ in Cluster & 70.00 & 39.50 & 82.20 & 65.70 \\
\hline & $\%$ in Sample & 44.70 & 16.00 & 39.40 & 100.00 \\
\hline \multirow{3}{*}{$\begin{array}{l}\text { Clinical } \\
\text { sample }\end{array}$} & $n$ & 18 & 23 & 8 & 49 \\
\hline & $\%$ in Cluster & 30.00 & 60.50 & 17.80 & 34.30 \\
\hline & $\%$ in Sample & 36.70 & 46.90 & 16.30 & 100.00 \\
\hline \multirow{3}{*}{ Overall } & $n$ & 60 & 38 & 45 & 143 \\
\hline & $\%$ in Cluster & 100.00 & 100.00 & 100.00 & 100.00 \\
\hline & $\%$ in Sample & 42.00 & 26.60 & 31.50 & 100.00 \\
\hline$\chi^{2}(2)$ & $17.55^{* * *}$ & & & & \\
\hline$V$ & 0.35 & & & & \\
\hline
\end{tabular}

Table 4

Comparison of clusters with different profiles of identity-related senses

\begin{tabular}{lcccccc}
\hline Variable & $\begin{array}{c}\text { Identity Cluster } 1 \\
(n=104)\end{array}$ & $\begin{array}{c}\text { Identity Cluster } 2 \\
(n=21)\end{array}$ & $\begin{array}{c}\text { Identity Cluster } 3 \\
(n=18)\end{array}$ & $H$ & Post-hoc & $\eta^{2}$ \\
\cline { 2 - 4 } & $M(S D)$ & $M(S D)$ & $M(S D)$ & & \\
\hline SIC & $1.74(0.21)$ & $2.38(0.38)$ & $1.62(0.49)$ & $41.28^{* * *}$ & $3,1<2$ & .29 \\
SU & $1.50(0.26)$ & $1.76(0.48)$ & $1.08(0.37)$ & $25.63^{* * *}$ & $3<1<2$ & .18 \\
SOB & $1.48(0.27)$ & $1.68(0.44)$ & $1.07(0.50)$ & $21.11^{* * *}$ & $3<1<2$ & .15 \\
SC & $1.50(0.21)$ & $2.06(0.31)$ & $1.27(0.34)$ & $50.78^{* * *}$ & $3<1<2$ & .36 \\
SCT & $1.77(0.61)$ & $1.75(0.52)$ & $1.06(0.60)$ & $16.75^{* * *}$ & $3<2,1$ & .12 \\
SSW & $1.61(0.24)$ & $2.09(0.28)$ & $0.81(0.48)$ & $64.82^{* * *}$ & $3<1<2$ & .46 \\
\hline
\end{tabular}

Note. SIC - sense of having inner contents, SU - sense of uniqueness, SOB - sense of one's own boundaries, SC - sense of coherence, SCT - sense of continuity over time, SSW - sense of self-worth, ${ }^{* * *} p<.001$ 
Table 5

Analysis of association between identity clusters and sample membership

\begin{tabular}{|c|c|c|c|c|c|}
\hline & & $\begin{array}{l}\text { Identity } \\
\text { Cluster } 1\end{array}$ & $\begin{array}{l}\text { Identity } \\
\text { Cluster } 2\end{array}$ & $\begin{array}{l}\text { Identity } \\
\text { Cluster } 3\end{array}$ & Overall \\
\hline \multirow{3}{*}{$\begin{array}{l}\text { Non-clinical } \\
\text { sample }\end{array}$} & $n$ & 92 & 1 & 1 & 94 \\
\hline & $\%$ in Cluster & 88.50 & 4.80 & 5.60 & 65.70 \\
\hline & $\%$ in Sample & 97.90 & 1.10 & 1.10 & 100.00 \\
\hline \multirow{3}{*}{$\begin{array}{l}\text { Clinical } \\
\text { sample }\end{array}$} & $n$ & 12 & 20 & 17 & 49 \\
\hline & $\%$ in Cluster & 11.50 & 95.20 & 94.40 & 34.30 \\
\hline & $\%$ in Sample & 24.50 & 40.80 & 34.70 & 100.00 \\
\hline \multirow{3}{*}{ Overall } & $n$ & 104 & 21 & 18 & 143 \\
\hline & $\%$ in Cluster & 100.00 & 100.00 & 100.00 & 100.00 \\
\hline & $\%$ in Sample & 72.70 & 14.70 & 12.60 & 100.00 \\
\hline$\chi^{2}(2)$ & $87.45^{* * *}$ & & & & \\
\hline$V$ & 0.78 & & & & \\
\hline
\end{tabular}

tions were calculated. The data presented in Table 6 show that more frequent use of primitive defense mechanisms and identity diffusion were associated with the weakening of all identity-related senses, except the sense of uniqueness (avg. $r=-.26$ and $r=-.34$ for maturity of defense mechanisms and identity integration, respectively). Reality-testing impairments, high levels of aggression, and deterioration of superego functioning were related to deficits in four identity-related senses. In cases of reality testing skills and level of aggression these were deficits concerning senses of having inner contents, coherence, continuity over time, and self-worth (avg. $r=-.24$ and $r=-.27$ for reality testing skills and level of aggression, respectively), whereas in the case of superego functioning - senses of having inner contents, one's own boundaries, coherence, and continuity over time (avg. $r=-.22$ ).

Next, it was checked whether the distinguished levels of personality organization are accompanied by differences in the intensity of identity-related senses. Analysis of variance (see Table 7) showed that the three clusters differed from one another in terms of four identity-related senses, i.e., senses of having

Table 6

Correlation matrix of personality dimensions and identity-related senses

\begin{tabular}{|c|c|c|c|c|c|c|c|c|c|c|}
\hline Variable & 2 & 3 & 4 & 5 & 6 & 7 & 8 & 9 & 10 & 11 \\
\hline 1. PD & $.71^{* * *}$ & $.52^{* * *}$ & $.47^{* * *}$ & $.53^{* * *}$ & $-.27^{* * *}$ & .02 & $-.20^{*}$ & $-.17^{*}$ & $-.31^{* * *}$ & $-.34^{* * *}$ \\
\hline 2. ID & - & $.60^{* * *}$ & $.57^{* * *}$ & $.55^{* * *}$ & $-.37^{* * *}$ & -.02 & $-.25^{* *}$ & $-.25^{* *}$ & $-.41^{* * *}$ & $-.44^{* * *}$ \\
\hline 3. RT & & - & $.58^{* * *}$ & $.59^{* * *}$ & $-.26^{* *}$ & .01 & -.15 & $-.18^{*}$ & $-.34^{* * *}$ & $-.19^{*}$ \\
\hline 4. $A G$ & & & - & $.52^{* * *}$ & $-.23^{* *}$ & -.09 & -.13 & $-.20^{*}$ & $-.33^{* * *}$ & $-.33^{* * *}$ \\
\hline 5. MV & & & & - & $-.21^{*}$ & .07 & $-.25^{* *}$ & $-.18^{*}$ & $-.25^{* *}$ & -.13 \\
\hline 6. SIC & & & & & - & .14 & $.18^{*}$ & $.58^{* * *}$ & $.25^{* *}$ & $.46^{* * *}$ \\
\hline 7. SU & & & & & & - & .08 & $.21^{*}$ & .01 & $.36^{* * *}$ \\
\hline 8. SOB & & & & & & & - & $.33^{* * *}$ & $.21^{*}$ & $.34^{* * *}$ \\
\hline 9. SC & & & & & & & & - & $.34^{* * *}$ & $.54^{* * *}$ \\
\hline 10. SCT & & & & & & & & & - & $.36^{* * *}$ \\
\hline 11. SSW & & & & & & & & & & - \\
\hline
\end{tabular}

Note. PD - primitive defenses, ID - identity diffusion, RT - reality testing, AG - aggression, MV - moral values, SIC - sense of having inner contents, SU - sense of uniqueness, SOB - sense of one's own boundaries, SC - sense of coherence, SCT - sense of continuity over time, SSW - sense of self-worth, ${ }^{* *} p \leq .001,{ }^{* *} p<.01,{ }^{*} p<.05$ 
Table 7

Comparison of personality clusters in terms of identity-related senses

\begin{tabular}{|c|c|c|c|c|c|c|}
\hline Variable & $\begin{array}{c}\text { Personality } \\
\text { Cluster } 1 \\
\quad(n=60)\end{array}$ & $\begin{array}{c}\text { Personality } \\
\text { Cluster } 2 \\
(n=38)\end{array}$ & $\begin{array}{c}\text { Personality } \\
\text { Cluster } 3 \\
(n=45)\end{array}$ & $H$ & Post-hoc & $\eta^{2}$ \\
\hline & $M(S D)$ & $M(S D)$ & $M(S D)$ & & & \\
\hline SIC & $1.84(0.36)$ & $1.65(0.35)$ & $1.92(0.37)$ & $12.73^{* *}$ & $2<1,3$ & .09 \\
\hline SU & $1.47(0.31)$ & $1.47(0.46)$ & $1.52(0.33)$ & 1.09 & - & .01 \\
\hline SOB & $1.46(0.38)$ & $1.34(0.44)$ & $1.56(0.25)$ & 5.44 & - & .04 \\
\hline SC & $1.56(0.33)$ & $1.45(0.34)$ & $1.64(0.30)$ & $8.84^{*}$ & $2<3$ & .06 \\
\hline SCT & $1.76(0.59)$ & $1.28(0.62)$ & $1.91(0.58)$ & $18.74^{* * *}$ & $2<1,3$ & .13 \\
\hline SSW & $1.63(0.39)$ & $1.32(0.57)$ & $1.71(0.26)$ & $12.26^{* *}$ & $2<1,3$ & .09 \\
\hline
\end{tabular}

Note. SIC - sense of having inner contents, SU - sense of uniqueness, SOB - sense of one's own boundaries, SC - sense of coherence, SCT - sense of continuity over time, SSW - sense of self-worth, ${ }^{* * *} p \leq .001,{ }^{* *} p<.01,{ }^{*} p<.05$

inner contents, coherence, continuity over time, and self-worth. The values of eta-squared indicate that the division of the study sample into clusters with different types of personality organization explained approximately $10 \%$ of the variance in these particular identity-related senses. The intensity of the identityrelated senses was found to be the highest in cluster 3, i.e., the most mature personality cluster, which was dominated by participants from the non-clinical group. The lowest intensity of the identity-related senses was observed in cluster 2, i.e., the least mature personality cluster, which was, in the majority, composed of individuals with mental disorders.
We then proceeded to check if the levels of personality organization correspond not only to different levels but also to different configurations of identity-related senses. Analysis by the $\chi^{2}$ test revealed a significant relationship between the type of personality organization and the type of configuration of identity-related senses, $\chi^{2}(4)=14.65, p=.005$ (see Table 8 ). Among participants with the most mature personality (cluster 3$)$, the vast majority $(82.20 \%)$ had harmonized identity structure and received scores that were close to the overall mean for all identity-related senses (cluster 1). Among those experiencing clear disturbances in the sense of identity (cluster 3 ),

Table 8

Analysis of association between personality clusters and identity clusters

\begin{tabular}{|c|c|c|c|c|c|}
\hline & & $\begin{array}{l}\text { Identity } \\
\text { Cluster } 1 \\
\end{array}$ & $\begin{array}{l}\text { Identity } \\
\text { Cluster } 2 \\
\end{array}$ & $\begin{array}{l}\text { Identity } \\
\text { Cluster } 3 \\
\end{array}$ & Overall \\
\hline \multirow{3}{*}{$\begin{array}{l}\text { Personality } \\
\text { Cluster } 1\end{array}$} & $n$ & 46 & 8 & 6 & 60 \\
\hline & $\%$ in Identity Cluster & 44.20 & 38.10 & 33.30 & 42.00 \\
\hline & $\%$ in Personality Cluster & 76.70 & 13.30 & 10.00 & 100.00 \\
\hline \multirow{3}{*}{$\begin{array}{l}\text { Personality } \\
\text { Cluster } 2\end{array}$} & $n$ & 21 & 6 & 11 & 38 \\
\hline & $\%$ in Identity Cluster & 20.20 & 28.60 & 61.10 & 26.60 \\
\hline & $\%$ in Personality Cluster & 55.30 & 15.80 & 28.90 & 100.00 \\
\hline \multirow{3}{*}{$\begin{array}{l}\text { Personality } \\
\text { Cluster } 3\end{array}$} & $n$ & 37 & 7 & 1 & 45 \\
\hline & $\%$ in Identity Cluster & 35.60 & 33.30 & 5.60 & 31.50 \\
\hline & $\%$ in Personality Cluster & 82.20 & 15.60 & 2.20 & 100.00 \\
\hline \multirow{3}{*}{ Overall } & $n$ & 104 & 21 & 18 & 143 \\
\hline & $\%$ in Identity Cluster & 100.00 & 100.00 & 100.00 & 100.00 \\
\hline & $\%$ in Personality Cluster & 72.70 & 14.70 & 12.60 & 100.00 \\
\hline$\chi^{2}(4)$ & $14.65^{* * *}$ & & & & \\
\hline$V$ & 0.23 & & & & \\
\hline
\end{tabular}


the majority showed the least mature personality (cluster $2 ; 61.10 \%$ ).

\section{DISCUSSION}

The present study sought to provide an empirical illustration of Kernberg's theory, especially the part of it in which the author links the level of personality organization with the development and maturity of the sense of identity.

Comparative analyses showed that all psychic functions, regarded by Kernberg as crucial to personality organization, clearly differentiate individuals from the general (non-clinical) population from individuals with mental disorders. A similar conclusion can be drawn from the results of classification analysis. The attempt to develop a typology of participants based on personality dimensions allowed three groups that differed significantly on each dimension to be distinguished. The following analysis revealed that the group with the lowest level of personality organization mostly comprised individuals with a psychiatric diagnosis, whereas the group with the highest level of personality functioning was dominated by participants from the non-clinical sample.

With regard to identity-related senses, differences between non-clinical and clinical groups were more limited. This could suggest that indices that are more closely associated with personality structure are more useful in diagnosis of psychopathology than indices that relate to one's experience of personal identity. This is understandable, given the fact that the mechanisms and processes of personality are considered more basic. Their quality determines the person's capacity for intrapsychic and interpersonal functioning, and thus underlies the phenotypic characteristics relating to subjective experience and behavior (Izdebska \& Pastwa-Wojciechowska, 2013). It is worth noting here that classification analysis, which employed specific configurations of identity-related senses, provided more conclusive findings. The most harmonized identity structure was characteristic, almost exclusively, of individuals from the non-clinical group, whereas the vast majority of individuals with a psychiatric diagnosis had disharmonized identity structure, with evidence of some rigidity, or demonstrated significant deficits in the sense of identity.

Examination of relations between dimensions of personality and identity-related senses yielded a clear picture of the associations between the level of personality functioning and the way of experiencing one's own identity. These findings can be taken as evidence which empirically supports the assumptions behind Kernberg's models and favors the formulations of the object relation theory (Kernberg, 1975, 1984, 1996, 2006). The obtained results indicated that differences in basic dimensions of personality organization accord well with expected differences in the sense of identity. In subsequent analysis, participants with the highest level of personality organization systematically scored higher on identity-related senses, and were characterized by a more harmonized configuration of identity-related senses than those with a personality organized at the lower level.

There are a few methodological limitations to the study. First, the compared groups were not matched or controlled for many variables (e.g., demographic, socioeconomic). Although there were no gender differences in any of the personality or identity variables considered, and only one significant age difference was identified, it is still possible that other unmeasured factors confounded, at least to some extent, the overall results. Certainly, further investigations, with larger and well-matched samples, would be worth undertaking.

Another limitation is the relatively small size and the diagnostic heterogeneity of the patient group, which, although fitting the purpose of representing the clinical population, makes it difficult to draw more specific conclusions. Since Kernberg himself assigned different psychopathological syndromes to different levels of personality organization (e.g., Caligor, Kernberg, \& Clarkin, 2007), further studies, with more homogeneous samples, are warranted to clarify the observed associations.

Also, a weakness of this investigation is the reliance on self-report measures. Even though all patients were deemed eligible to participate by the treating clinician, the findings may be challenged by the question whether those with severe mental illness (including schizophrenia and mood disorders) were able to accurately perceive themselves and had the cognitive ability to respond to the self-report measures.

\section{CONCLUSIONS}

In conclusion, the results of the present study generally confirmed the hypotheses derived from Kernberg's theory about the relationships between personality structure, mental pathology, and subjective self-experience. Firstly, it was demonstrated that there is a relationship between the level of personality organization and the maturity of the sense of personal identity. Secondly, as expected, individuals with mental disorders showed greater levels of personality pathology and a more disorganized sense of personal identity, when compared with individuals from the general population. The current observations would benefit greatly from future studies in larger and more homogeneous study populations. More rigorous selection criteria and greater control over potential confounders would probably allow us to go further in examining the theoretical salience 
and diagnostic utility of Kernberg's model of personality organization.

\section{ENDNOTES}

1 Data were collected by Ewelina Chmurska and Joanna Korzeniowska under the supervision of the second author.

2 It should be noted that some patients in the study sample had more than one disorder diagnosed, which made it difficult to determine which diagnosis was primary.

\section{References}

Caligor, E., Kernberg, O. F., \& Clarkin, J. F. (2007). Handbook of dynamic psychotherapy for higher level personality pathology. New York: American Psychiatric Publishing.

Clarkin, J. F., Foelsch, P. A., \& Kernberg, O. F. (2001). The inventory of personality organization. New York: The Personality Disorder Institute, Cornell University.

Grabski, B., \& Gierowski, J. K. (2012). Zaburzenia osobowości - różne spojrzenia i próby ich integracji [Personality disorders - different outlooks and attempts at their integration]. Psychiatria Polska, 46, 829-844.

Izdebska, A., \& Pastwa-Wojciechowska, B. (2013). Organizacja osobowości i jej pomiar - polska adaptacja kwestionariusza IPO Kernberga i współpracowników [Organization of personality and its measurement - Polish adaptation of the IPO questionnaire by Kernberg and colleagues]. Czasopismo Psycholologiczne, 19, 17-27.

Kernberg, O. F. (1975). Borderline conditions and pathological narcissism. New York, NY: Jason Aronson.

Kernberg, O. F. (1984). Object relations theory and clinical psychoanalysis. New York, NY: Jason Aronson.

Kernberg, O. F. (1996). A psychoanalytic theory of personality disorders. In: J. F. Clarkin \& M. F. Lenzenweger (eds.), Major theories of personality disorder (pp. 106-141). New York, NY: Guilford Press.

Kernberg, O. F. (2006). Identity: Recent findings and clinical implications. Psychoanalytic Quarterly, 75, 969-1004.

Millon, T., \& Davis, R. (2005). Zaburzenia osobowości we wspótczesnym świecie [Personality disorders in modern life]. Warsaw: Instytut Psychologii Zdrowia PTP.

Morey, L., Berghuis, H., Bender, D., Verheul, R., Krueger, R., \& Skodol, A. (2011). Toward a model for assessing level of personality functioning in DSM-5, part I: A review of theory and methods. Journal of Personality Assessment, 93, 332-346.
Morey, L., Berghuis, H., Bender, D., Verheul, R., Krueger, R., \& Skodol, A. (2011). Toward a model for assessing level of personality functioning in DSM-5, part II: Empirical articulation of a core dimension of personality pathology. Journal of Personality Assessment, 93, 347-353.

Moskalewicz, J., Kiejna, A., \& Wojtyniak, B. (eds.). (2012). Kondycja psychiczna mieszkańców Polski: raport z badań „Epidemiologia zaburzeń psychiatrycznych i dostęp do psychiatrycznej opieki zdrowotnej" - EZOP Polska [Mental condition of the Polish population: report from the study "Epidemiology of mental disorders and access to mental health care. EZOP - Poland"]. Warsaw: Instytut Psychiatrii i Neurologii.

Pilarska, A. (2012). Wielowymiarowy Kwestionariusz Tożsamości [Multidimensional Questionnaire of Identity]. In: W. J. Paluchowski, A. Bujacz, P. Haładziński, \& L. Kaczmarek (eds.), Nowoczesne metody badawcze w psychologii [Modern research methods in psychology] (pp. 167-188). Poznań: Wydawnictwo Naukowe WNS UAM.

Pilarska, A., \& Suchańska, A. (2013). Strukturalne właściwości koncepcji siebie a poczucie tożsamości. Fakty i artefakty w pomiarze spójności i złożoności koncepcji siebie [The relationship between structural aspects of self-concept and personal identity. Facts and artifacts in the measurement of self-concept complexity and coherence]. Studia Psychologiczne, 51, 29-42. 